\title{
Designing a practical and rigorous framework for comprehensive evaluation and prioritisation of environmental projects ${ }^{*}$
}

Running head: Evaluation of environmental projects

David J. Pannell ${ }^{\mathrm{A}, \mathrm{C}, \mathrm{E}}$, Anna M. Roberts ${ }^{\mathrm{B}, \mathrm{C}}$, Geoff Park ${ }^{\mathrm{C}, \mathrm{D}}$ and Jennifer Alexander ${ }^{\mathrm{B}}$

${ }^{A}$ School of Agricultural and Resource Economics, University of Western Australia, 35 Stirling Highway, Crawley, WA, Australia 6009

${ }^{\mathrm{B}}$ Department of Primary Industries, RMB 1145 Rutherglen, Victoria, Australia 3685

${ }^{\mathrm{C}}$ Future Farm Industries Cooperative Research Centre, Crawley, WA Australia 6009

${ }^{D}$ North Central Catchment Management Authority, Huntly, Victoria, Australia 3551

${ }^{\mathrm{E}}$ Corresponding author. Email: David.Pannell@uwa.edu.au

\section{Abstract}

Context. A framework was developed to help investors improve the delivery of environmental benefits from environmental programs. The framework, INFFER (Investment Framework for Environmental Resources), assists environmental managers to design projects, to select delivery mechanisms, and to rank competing projects on the basis of benefits and costs.

Aims. To identify design requirements for an environmental investment framework based on consideration of lessons from practical experience, and established theory from decision analysis and economics.

Methods. The design and delivery of the framework are based on extensive experience from working with environmental managers and policy makers. In addition, the developers have

\footnotetext{
* Published as: Pannell, D.J., Roberts, A.M., Park, G. and Alexander, J. (2013). Designing a practical and rigorous framework for comprehensive evaluation and prioritisation of environmental projects, Wildlife Research 40(2), 126-133. http://dx.doi.org/10.1071/WR12072
} 
paid close attention to the need for processes that are theoretically rigorous, resulting in a tool that allows valid comparison of projects for different asset types, of different scales and durations.

Key results. From the practical experience outlined, a number of important lessons and implications are identified, including the need for: simplicity, training and support of users, trusting relationships with users, transparency, flexibility, compatibility with the needs and contexts of users, and supportive institutional arrangements. Use of a theoretically correct metric to rank projects can deliver dramatically improved environmental values relative to a commonly used weighted additive metric.

Conclusions. Practical and theoretical considerations have strong implications for the design of a practical, effective and accurate tool to support decision making about environmental project priorities.

\section{Introduction}

In common with other developed countries, Australia has invested billions of dollars of public funds in projects intended to improve the condition of natural resources and the environment and to protect biodiversity. However, there have been criticisms of some of these investments, including for their poor performance in delivering the intended environmental benefits (Auditor General 2008). Reasons identified for this poor performance include: poor selection of priorities (or absence of prioritisation); poor design of projects, including poor selection of delivery mechanisms ${ }^{\dagger}$; and poor monitoring and evaluation resulting in a failure to learn from past programs (Pannell and Roberts 2010).

The quality of decision making by environmental managers may be enhanced by use of formal decision frameworks to assist with the development and evaluation of prospective projects. Various decision tools and frameworks have been used in biodiversity conservation. Examples include Assets, Threats and Solvability (ATS) (Hajkowicz and McDonald 2006), Conservation

\footnotetext{
${ }^{\dagger}$ Delivery mechanisms are the instruments used in a project to attempt to bring about the desired changes in environmental management. They may include information-based approaches (education, training, awareness raising, support for social networks), regulation, research and development, direct management by the project, or incentive-based approaches including payments for ecosystem services, or market-based instruments such as offsets (McKenney and Kiesecker 2010), conservation auctions (Stoneham et al. 2003) emissions taxes or tradeable permit schemes (Pezzey 2003).
} 
Action Planning (CAP) ${ }^{\ddagger}$, Multicriteria Landscape Assessment and Optimisation (MULBO) (Meyer and Grabaum 2008) and Benefit: Cost Analysis (Boardman et al. 2010). These existing tools have various strengths. However, following extensive experience working with environmental organisations to help them assess their priorities, we judged that none of the existing tools provided an ideal combination of usability, rigour and comprehensiveness. None is designed to assist environmental organisations to undertake the full range of tasks that we considered to be essential for investment planning: initial project identification, development of well-costed and logically consistent environmental projects for public funding, and prioritisation of the available projects. None of the available tools include the capacity to analyse the choice of delivery mechanisms to be used in the project, which was identified as an important weakness in many existing programs. For example, the National Action Plan for Salinity and Water Quality was a major ( $\$ 1.4$ billion) program operating in Australia from 2001 to 2008, which relied primarily on extension and communication activities, although analyses of the salinity problem revealed that extension was not an appropriate mechanism in most cases (Ridley and Pannell 2005; Pannell and Roberts 2010). Some of the decision tools do not support project prioritisation (Conservation Action Planning) while others do prioritise but not on the basis of a sound measure of cost-effectiveness (ATS). Some are too complex or specialised for application by non-expert users (Benefit: Cost Analysis). Most do not explicitly consider landholder behaviour when prioritising actions (ATS, MULBO), although the success of many projects is sensitive to the level of landholder cooperation that is achieved.

INFFER (Investment Framework for Environmental Resources) (Pannell et al. 2012) was developed to fill the identified gap. It is intended to help investors to improve the delivery of benefits from programs that aim to protect or enhance particular environmental assets. It is a tool that allows users to prioritise among competing projects based on the benefits and costs of each project. It also assists with the development and design of projects, and with the selection of delivery mechanisms. It is designed to maximise the learning from experience that should occur in these programs.

Usage of INFFER has grown steadily over time, since the first version became available in 2008. Of the 56 regional environmental management bodies in Australia, 20 have piloted or

\footnotetext{
$\$$ http://conserveonline.org/workspaces/cbdgateway/cap/index_html (accessed 5 April 2012)
} 
used INFFER to various degrees and in various ways. Some have adopted individual components, while others are using the whole framework as an integrated process. There has been training of government officers from five state agencies in Australia and in four Canadian Provinces. It has been used by environmental consultants or non-government organisations in four Australian states (Western Australia, Victoria, Queensland and New South Wales) and two Canadian provinces (Alberta, Manitoba). The project team itself has applied INFFER to real-world problems (e.g. the Gippsland Lakes in Victoria, Roberts et al. 2012).

In the development of INFFER, close attention was paid to two issues: its usability, acceptability and usefulness to users, and its theoretical rigour. The purpose of this paper is to describe how and why INFFER was designed in the way it was, covering both practical and theoretical aspects. Questions addressed are: (a) given extensive practical experiences with environmental decision tools and investment frameworks, how should this tool be designed and implemented to be adopted widely and effectively by users who lack strong expertise in formal decision analysis? and (b) what are the requirements for the framework to be consistent with established theory in order to be able to identify those projects with the greatest expected environmental benefits?

\section{Overview of INFFER}

Here we provide a brief overview of INFFER to prepare readers for later sections that examine its practical and theoretical underpinnings. Refer to Pannell et al. (2012) for a more detailed description of the framework.

The framework includes a step-by-step process, summarised in Figure 1. It begins by collating an inventory of important environmental assets. This step includes consultation with the community, environmental agencies, experts and other stakeholders to identify assets in the relevant region and capture information about their values, threats and feasibility of management.

In Step 2, the assets are subjected to a relatively simple filtering process to identify projects that appear attractive enough for detailed project development and assessment to be worthwhile. The filtering process is simple in recognition of the fact that any environmental manager faces a vast number of potential projects that could be undertaken - far too many for it to be possible to conduct a comprehensive assessment of every project. It is not necessary to 
be highly precise about which projects proceed to the next stage of the process. The accepted aim in Step 2 is to find good projects, not necessarily the absolute best projects. Criteria typically used in the filtering step are asset value, threat and feasibility, as these are key determinants of project benefits. The filtering is usually conducted by a committee that includes experts, managers and, sometimes, well-informed community members.

Figure 1 near here.

Projects that pass the filtering process of Step 2 proceed to a comprehensive analysis in Step 3, using an online template called the Project Assessment Form. This involves calculation of a Benefit: Cost Ratio (BCR) to assess the value for money offered by each project, identification of an appropriate delivery mechanism for the project, testing of the project logic, and specification of a "SMART" goal for each project: one that is Specific, Measureable, Achievable, Relevant and Time-bound (Park et al. 2013). Information used in calculation of the BCR includes: the value of the environmental asset, expected environmental degradation without further intervention, the extent to which degradation can be avoided or reversed through intervention, the management actions sought by the project, the likely degree of adoption and compliance by land managers and other relevant organisations, various risks to project success, the time lag until project benefits would be realised, and the full range of relevant project costs in the short- and long-term, including private compliance costs. The formula used is presented in the Theoretical Underpinnings section later. Step 3 may be conducted by the environmental organisation or by consultants with expertise in the process. It typically involves assignment of a leader for each project assessment, with that leader responsible for consulting experts and collating existing information to complete a Project Assessment Form.

Sometimes, the quality of information used in Step 3 is not high enough to rely on for a final investment decision, highlighting the need for a feasibility assessment in Step 4, involving targeted collection of additional information. This is used to update and reconsider the project assessment, allowing adaptive decisions about whether the project should be a priority and, if so, the project design. This is particularly important for projects with large budgets, to avoid funding being committed to projects that turn out to have serious weaknesses.

Complete documentation of the process is publicly available at www.inffer.org, including a detailed user's guide, and an extensive list of frequently-asked questions. A formal training 
program is offered, and users receive one-to-one support and feedback on the data and assumptions used in their project assessments.

\section{Practical underpinnings}

\section{Experience informing the design}

INFFER is strongly founded on a practical understanding of the decision making environment for environmental managers. Prior to commencing the development of the framework, the project team had substantial relevant experience to draw on.

Members of the team had initiated and co-developed the Salinity Investment Framework (SIF1 and SIF2) in Western Australia. SIF1 was piloted with a regional natural resource management (NRM) body and SIF1 and SIF2 were piloted with three state government agencies (McAlinden et al. 2003; Sparks et al. 2006; Cleland 2008). Subsequently, the team developed Salinity Investment Framework III (SIF3) (Ridley and Pannell 2005; Pannell 2008), which was piloted with two regional NRM bodies, one in Western Australia and one in Victoria (Roberts and Pannell 2009; Pannell et al. 2008).

Several complementary research projects were conducted. There was a survey of 17 regional NRM bodies, to understand their skills and capacities and areas of weakness for decision making (Seymour et al. 2008). Adoption of conservation practices by rural landholders was reviewed (Pannell et al. 2006). Responses to environmental projects by rural lifestyle landholders was researched (Pannell and Wilkinson 2009).

As a result of the above activities and extensive engagement with relevant government agencies in four states and nationally (Pannell and Roberts 2009), the team developed good knowledge of decision processes at regional, state and national levels and of policy processes in governments (Pannell 2005). This information provided guidance on features and facilities that would be beneficial in the tool.

In addition, since development of the first version of INFFER was completed, it has been extensively modified in response to feedback from users and stakeholders. Surveys of users were conducted to identify improvements. 


\section{Lessons learnt}

The practical experiences, engagement and research outlined above revealed a number of lessons that have influenced the design of INFFER. The first set of lessons related to weaknesses in existing decision processes. The team observed that existing decision making about funding of environmental projects often does not involve rigorous analysis of the relative merits of competing projects. There have been attempts to use analysis to prioritise projects in some cases, but these have tended to consider only a sub-set of the relevant information. Rigorous, comprehensive feasibility studies are generally not undertaken prior to proceeding with large environmental investments.

Pannell (2008) highlighted the importance of selecting appropriate delivery mechanisms for effective environmental projects. However, as noted earlier, some programs employ mechanisms that are unlikely to be effective (e.g. Pannell and Roberts 2010).

In order to be able to compare the merits of competing projects, it is necessary for each project to be specified in ways that are logically consistent, in the sense that the planned interventions will actually deliver the intended on-ground change, the intended on-ground works are sufficient to deliver the project's goals, and the project costs are accurately reflected in its budget. The project team has observed that these requirements are often not met.

The second set of lessons relate to the skills, capacities, resources and perceptions of environmental managers. In many environmental management bodies, there is a lack of capacity to formally integrate disparate technical and socio-economic information for decision making. Participants are used to relatively simple decision processes and can feel that a systematic, comprehensive process is unnecessarily difficult and time consuming. They are unaware of the extent to which stronger decision processes can contribute to the achievement of environmental benefits.

There is a lack of knowledge within environmental management bodies of how to use monitoring to support learning and inform adaptive management. Most monitoring is used only for reporting purposes. Other areas where the knowledge of environmental managers appears insufficient include economics and social science (Seymour et al. 2008).

The third set of lessons relates to the paradigm within which environmental managers make their decisions about project design and prioritisation. Related to the lack of economics 
expertise noted above, some employees and stakeholders hold antagonistic views towards economics, reducing the prospects for acceptance of more rigorous, systematic analysis.

Amongst some environmental bodies, there has been reluctance to target investment to those projects that are likely to deliver the most valuable results. A process of targeting investment would conflict with a common philosophy of encouraging broad participation by many landholders, a philosophy that tends to overlook the fact that different landholders make different contributions to desired environmental improvements. Reflecting this perspective, many respondents to a survey of the staff of regional NRM bodies did not support a strong focus on environmental effectiveness in their decision processes (Marsh et al. 2010).

Some decision makers are resistant to the idea of estimating the relative values of different environmental assets. They feel that all environmental assets are important, and all should be protected. Some particularly dislike the concept of non-market valuation. Even a softer approach, based on a scoring system, still makes some uncomfortable. They express concerns about the subjective nature of any scoring system used to value environmental assets, perhaps overlooking the fact that subjective valuation of environmental resources is already implicitly undertaken in existing decision processes.

The last set of lessons relates to the institutional context within which decisions about project design and priorities are made. Environmental managers often have to develop projects or plans very quickly, reducing the resulting quality of those plans and projects. Although it is predictable that plans and projects will need to be developed to meet future deadlines, it rarely happens before those deadlines are looming, due to the multitude of other demands on people's time. Even if time were not a pressing concern, the number of potential projects is so large that it is not feasible to do comprehensive assessments of every one. Indeed, in practice, only a minority of potential projects can be fully assessed.

Some environmental managers do not expect that the benefits (in terms of increased funding success) from undertaking more rigorous decision analysis are likely to be sufficient to justify the resources required. They may employ simple and non-analytical decision making processes in the expectation that they will suffer little or no penalty for doing so. 


\section{Consequences for the decision tool}

The insights described above influenced the design and implementation of INFFER. For example, the framework is designed to elicit and integrate all relevant information for prioritising projects (as outlined in the next section). In response to weaknesses identified in existing processes, it includes guidance on the appropriate choice of delivery mechanisms and includes checks on the logical consistency of project specifications.

The framework has been designed to be simple without overly compromising rigour and comprehensiveness. It is structured to be capable of comparing projects for different types of environmental assets, different threats, different scales and different time frames. While retaining rigour, it can deal efficiently with very large numbers of candidate projects, not bogging down users with too much analysis.

Training and support for users is provided because experience indicates that most users will not apply the tool well if left to learn about it from written material alone. Nevertheless, comprehensive written documentation is essential to support the training process, to support the learning of those users who do prefer to learn by reading, and to facilitate review and critique of the approach.

Adoption of INFFER by some organisations will need to be accompanied by cultural change. This reinforces the need for good training and support, and for development of strong, trusting relationships with users.

Because different users have different preferences for how they use a tool like INFFER, it needs to be flexible and amenable to adaptation to fit users' needs. To support this, documentation includes a discussion of a variety of ways in which INFFER can be used.

Adoption of systematic decision tools by environmental managers would be assisted by supportive changes in institutional arrangements, including rewards for organisations that make appropriate use of sound decision methods. The project team works with funders and policy makers to create an awareness of this need and to support their efforts to modify the incentives for environmental managers to improve their decision processes. 


\section{Theoretical underpinnings}

As well as being practical, the aim is for the process to be theoretically rigorous. In this section, we describe several aspects of theory that underpin the approach, and explain the theoretical basis of several compromises that were made to enhance simplicity and usability. The issues described here relate to Step 3 (Figure 1), in which individual projects are developed and assessed in detail.

\section{Metric for project ranking}

Part of Step 3 is designed to be consistent with Benefit: Cost Analysis (BCA) (Boardman et al. 2010), including calculation of a Benefit: Cost Ratio (BCR) for each project. The use of a BCR to rank projects allows theoretically sound comparison of projects of different types and different scales. Carwardine et al. (2008) showed that failure to consider project cost appropriately can lead to important mistakes in the prioritisation of environmental projects. Dividing estimated benefits by costs (as in a standard Benefit: Cost Ratio, and as adopted by the Project Prioritization Protocol of Joseph et al. 2009) ensures that a ranking of projects will result in selection of the projects that provide the most valuable environmental benefits given a limited budget.

As outlined by Pannell et al. (2012), the BCR is calculated as follows.

$$
B C R=\frac{V P P B \times A \times(1-R F) \times D F}{T P V E P C}
$$

where

$V P P B=$ the value of potential project benefits, assuming that the required works are fully adopted, and that there are no risks to project success and no time lags. In a BCA, this is expressed in dollar terms (even for non-financial or intangible environmental benefits). Factors considered in estimating VPPB are the value of the environmental asset, and proportion of the asset's value would be protected or improved as a result of the project, assuming that it is immediately successful (see Pannell et al. (2012) for details of how these, and other specific variables mentioned below, are included in the formula).

$A=$ the proportion of required adoption of new works and actions that is expected to be achieved by the project. By definition, this is a proportion. The structure of equation (1) 
(with the numerator multiplied by A) implies that benefits are proportional to the level of adoption. If full adoption is assured (e.g., the required works and actions will be undertaken by the organisation running the project) then $A=1$. If adoption must be undertaken by private landholders or by another organisation, $A<1$ would usually be expected.

$R F=$ the risk of failure of the project, so $(1-R F)$ represents the probability that the project will not fail. Risks considered are failure due to poor technical feasibility of the project; adoption of new, adverse practices by private landholders; social or political resistance to the project; and failure to obtain essential long-term funding to maintain the project's benefits. Since this term is a probability, the BCR calculated is an 'expected' $\mathrm{BCR}$, in the statistical sense of it being weighted by a probability.

$D F=$ the discount factor for the time lag on benefits. Consistent with standard economic theory, the discount factor is calculated as $D F=1 /(1+r)^{L}$, where $L=$ time lag until the majority of anticipated benefits from the project occur (years) and $r$ is the real discount rate, assumed to be $5 \%$. The way that discounting of benefits enters the formula in equation (1) is correct for a situation where the benefits of the project begin after a certain time lag and are then sustained forever.

TPVEPC = total present value of expected project costs, in dollars. As with the benefits, future costs should also be discounted to their present value. Factors included in this variable are the costs of the current proposed project (total over the project's funded life - usually three to five years), the long term cost of maintaining the project's benefits, the probability that those maintenance costs will not be obtained, and the compliance costs borne by private landholders.

If $V P P B$ is measured in dollars, then, since $E P R A, R F$ and $D F$ are all proportions or probabilities, the numerator of equation (1) is also in dollars, and represents the expected value of project benefits. The multiplication of terms in the numerator is important to ensure that it accurately represents expected benefits. It is common for decision makers to use a different benefits-index formula in which these variables are weighted and added. However, that approach introduces error into the calculation and will result in prioritisation of projects that do not provide the greatest expected benefits. 
To illustrate, Figure 2 shows a comparison of the rankings of 100 simulated projects using the two alternative formulae (multiplicative and additive). For each simulated project, the parameters of equation (1) were generated randomly from uniform distributions. The rank of each project was determined for each formula, with low ranks being superior. For the purpose of this illustration, equal weights were assigned to the different variables in the additive formula.

Figure 2 near here.

The figure shows that project rankings based on the weighted additive formula do not correlate well with the rankings for the multiplicative formula. For the illustrated example, the $\mathrm{R}^{2}$ between the two sets of rankings is only 7 per cent. For this reason, the consequences for the environment of using the inferior additive formula can be severe. For example, the dashed lines in Figure 2 show the cut-off points for project selection if the program budget is five per cent of the level needed to fund all projects. (Selectivity of the order of five per cent is typical for Australian programs.) Projects to the left of the vertical dashed line would be selected using the multiplicative formula whereas projects lying below the horizontal dashed line would be selected using the additive formula. In this example, only one of the 16 projects that would be selected using the additive formula would be included in the set that provides the most valuable environmental outcomes for the available resources.

The environmental benefits delivered as a result of selecting projects using the additive formula would be 64 per cent lower in total value than the best projects, selected using the multiplicative formula. If this procedure is repeated for many sets of simulated projects, the expected loss of environmental values due to poor project selection is 52 per cent. Using the additive formula is only moderately better than selecting projects completely at random, which results in a 74 per cent loss of environmental values relative to using the multiplicative formula.

\section{Asset valuation}

One of the variables considered in the calculation of VPPB in equation (1) is the value of the environmental asset. This value is used to scale the benefits of the project, on the basis that the more valuable an environmental asset is considered to be, the greater are the potential benefits from a project that protects that asset. 
The asset value may reflect the benefits that it generates, or could generate, to the broad community, or it may reflect judgements about its intrinsic ecological or environmental value. One approach used is to ask users to score the asset value on a scale in which each point is worth $\mathrm{A} \$ 20$ million. A table of suggested values for various assets is provided to assist users to consider an appropriate value for the asset in question. Alternatively, users may provide dollar values for each asset based on market values and non-market valuation studies (e.g. Champ et al., 2003; Kanninen, 2007). It may be that an existing environmental valuation study is available for the asset, or that a new study is conducted.

The accuracy of the scoring approach depends on the ability of the environmental managers to accurately estimate asset values. The ability of environmental managers to estimate environmental values held by the community may be questioned. If this is of concern, then non-market valuation may be used. On the other hand, there is commonly a lack of evidence about community valuation of environmental assets, and conducting a new study is costly, so it may be considered that the judgements of environmental managers are a reasonable initial guide. Furthermore, the scoring approach is amenable to a participatory approach, involving consultation with experts, community members and managers. Marshall et al. (2011) consider this to be a strength of the approach:

"The INFFER process within which [Benefit: Cost Ratios] are calculated was designed to encompass a process of community consultation, and thus it provides scope to address criticisms of BCA [Benefit: Cost Analysis] due to the top-down manner in which it is normally applied. This consultative process allows stakeholders 'to express values and preferences for different NRM assets and to provide local knowledge about assets and their management ...'. Hence, it offers potential to address criticisms of BCA for valuing environmental and natural resource assets using the principle of individual sovereignty rather than on the basis of deliberation among affected parties" (Marshall et al. 2011, p. 95).

In practical terms, a system based on scores elicited from stakeholders and decision makers is more feasible and far less costly than a system requiring valuation surveys for each asset. The latter approach is clearly prohibitively expensive given the large number of assets and projects to be evaluated. 


\section{Accounting for time}

Environmental projects are likely to involve time lags related to both the benefits and the costs. To account for time lags, standard discounting methods are used. For simplicity, users are not asked to specify the discount rate - a standard real discount rate of 5 per cent is used in all analyses.

On the benefits side, after a project is implemented, it may be some years until the bulk of the environmental benefits are generated, either because the project is preventing degradation that would not have occurred for some time, or because it takes a long time for the works to take effect (e.g. it takes time for trees to grow). This lag is elicited from users in the course of them completing the Project Assessment Form, and is used to express future benefits in presentvalue terms.

On the cost side, a simplification in the procedure is to not discount costs occurring in the initial project that is being assessed (i.e. costs in the first 3 to 5 years). The Project Assessment Form also asks users to specify long-term maintenance costs required to preserve the benefits generated by the current project. For example, there may be a need for ongoing payments to landholders, or for monitoring and enforcement of agreements. These maintenance costs are assumed to be required annually for 20 years beyond the current project, and the stream of costs is discounted to calculate the present value of costs.

\section{Accounting for project risk}

As noted above, a number of risks are considered. For each of these risks, a probability of project failure due to the risk is elicited. A detailed representation of risk would elicit a joint probability distribution for results related to these uncertain variables, and use it to calculate the expected value of benefits. The approach involves a simplification in that we only allow for two possible outcomes for each risk; for example, we assume that the project either will fail completely due to technical infeasibility, or it will achieve its full potential as specified in the other collected data. Similarly, project success/failure is represented as a binary variable for the other three risk factors. This simplification requires users to subjectively define project 'success'. 


\section{Choice of delivery mechanisms}

INFFER includes an innovative framework for selection of delivery mechanisms that are most likely to be effective for a particular project: the Public: Private Benefits Framework (Pannell 2008, 2009). The framework helps the user to select the most appropriate category of delivery mechanism for the project, from five categories: extension, positive incentives, negative incentives, technology development and no action. Several of these are broad categories, encompassing a number of more specific mechanisms. Extension includes mechanisms such as education, training, awareness raising and support for social networks. The incentive mechanisms (positive and negative) include financial or regulatory instruments of various kinds, from polluter-pays mechanisms (e.g. command and control, pollution tax, offsets), to beneficiary-pays mechanisms (e.g. subsidies, conservation auctions and tenders), and tradable permits (Pannell 2008).

In the interests of space, the Public: Private Benefits Framework is not reproduced here. Interested readers are referred to Pannell $(2008,2009)$ or to summary information available at http://dpannell.fnas.uwa.edu.au/ppf.htm.

\section{Discussion}

The design of the framework involved striking a difficult balance between simplicity, to aid with ease of use, and comprehensiveness, to maintain the validity of results. Users who have been accustomed to much simpler and more partial planning approaches have needed a high level of training and support. Given the common neglect of cost-effectiveness as a consideration in environmental planning and prioritisation in Australian NRM programs, acceptance of the approach has required more than training in its mechanics. It requires support for a change in mindset, and in some cases even a change in organisational culture. Users need to be persuaded that it is worthwhile investing the time and effort into a more comprehensive and rigorous assessment.

We find that certain types of information required for project evaluation are consistently lacking or subject to high uncertainty. This is particularly true of information about the impacts of particular management actions on the environment, and the behavioural responses of individuals to specific delivery mechanisms. Concerns about the level and quality of information linking actions to environmental benefits have been expressed by other authors in 
Australia (e.g., Hajkowicz and McDonald 2006, Hajkowicz 2009) and internationally (e.g. Falconer and Saunders 2002; Weinberg and Claassen 2006).

Where final funding decisions are made external to the bodies which develop and evaluate projects, it is important to ensure that all assessments are conducted to an acceptable standard. We have found that regional NRM bodies want assessments conducted by other bodies with which they have to compete for funding to be subject to review and quality assurance. This is clearly an issue that is relevant to any project assessment process, not just this one.

There are many other tools available that can make a contribution to planning and prioritisation of environmental and natural resource investments. We have sometimes faced confusion among potential users about what different tools provide, and some incorrect perceptions that other tools were similar to or in competition with INFFER. In many such cases, we find that the other tools in question can often be used in a complementary way (e.g. by providing information to help undertake project assessment).

The importance of using a theoretically sound approach to selection of environmental projects is not widely recognised. Results presented here indicate that improvements in environmental values delivered from a portfolio of projects can be of the order of 100 per cent, simply by switching from the commonly-used weighted additive benefits metric to the more theoretically sound multiplicative formula of equation (1) (assuming that resources are sufficient to fund five per cent of projects). Other common weaknesses in metrics that are actually used to rank environmental projects include: failure to consider project costs at all; inclusion of project costs as a subtracted term rather than in the denominator; and omission of important variables from the benefits metric. Each of these weaknesses would further reduce the quality of decision making about project priorities, resulting in further losses of environmental values.

\section{Conclusion}

Development of a valid and useful investment framework for assessment of environmental projects requires close attention to issues of practicality and well as theoretical rigour. This paper has outlined how these issues have been considered and accommodated in the development and application of a new investment framework for environmental projects, INFFER. 
Based on extensive experience working with environmental managers in developing and using INFFER, and in previous projects, a number of important lessons for the design and implementation of the framework were identified. Key lessons include the need for simplicity, training and support, trusting relationships with users, transparency, flexibility, compatibility with the needs and contexts of users, and supportive institutional arrangements.

On the theoretical side, INFFER is consistent with the theoretical underpinnings of Benefit: Cost Analysis, while fostering a higher level of stakeholder participation than is usual in BCA. A key component is a Benefit: Cost Ratio, which has been carefully designed to ensure that it is theoretically consistent with the ranking of projects that will deliver the most valuable environmental benefits (unlike some commonly used metrics). Careful attention to the design of the tool and responsiveness to users' feedback have contributed to successful adoption of the tool by a number of environmental management bodies.

\section{Acknowledgements}

The authors are grateful to the large number of people who have contributed to the development of INFFER, notably April Curatolo, Sally Marsh, Melanie Strang, Graham Marshall, and many users who provided constructive feedback, especially the North Central Catchment Management Authority (board, CEO Damien Wells and other staff). Two anonymous referees provided helpful advice on the paper. Funding for the project was provided by Future Farm Industries Cooperative Research Centre, the Department of Primary Industries Victoria, the University of Western Australia, the Department of Sustainability and Environment Victoria, the Australian Research Council (Federation Fellowship Program) and the Australian Government's Department of Environment Water Heritage and the Arts (CERF Program).

\section{References}

Boardman, A., Greenberg, D., Vining, A. and Weimer, D. (2010). 'Cost-Benefit Analysis', 4th Edition. (Prentice Hall: Upper Saddle River NJ.)

Carwardine, J., Wilson, K.A., Watts, M., Etter, A., Klein, C.J. and Possingham, H.P. (2008). Avoiding costly conservation mistakes: The importance of defining actions and costs in spatial priority settings, PLoS One 3, Article number e2586.

Champ, P.A., Boyle, K.J. and Brown, T.C. (2003). 'A Primer on Nonmarket Valuation.' (Springer: Dordrecht.) 
Cleland, J. (2008). Western Australia's Salinity Investment Framework: A study of priority setting in policy and practice, PhD thesis, School of Agricultural and Resource Economics, University of Western Australia.

Falconer, K. and Saunders, C. (2002). Transaction costs for SSSIs and policy design, Land Use Policy 19, 157-166.

Hajkowicz, S. (2009). The evolution of Australia's natural resource management programs: Towards improved targeting and evaluation of investments, Land Use Policy 26, 471-478.

Hajkowicz, S. and McDonald, G. (2006). The Assets, Threats and Solvability (ATS) model for setting environmental priorities, Journal of Environmental Policy and Planning 8, 87-102.

Joseph, L.N., Maloney, R.F., Possingham, H.P. (2009). Optimal allocation of resources among threatened species: a project prioritization protocol, Conservation Biology 23, 328-38.

Kanninen, B.J. (Ed.) (2007). 'Valuing Environmental Amenities Using Stated Choice Studies: A Common Sense Approach to Theory and Practice.' (Springer: Dordrecht.)

Marsh, S.P., Pannell, D.J., Curatolo, A., Park, G. and Roberts, A.M., (2010). Lessons from implementing INFFER with regional catchment management organisations. Contributed paper to the 54 ${ }^{\text {th }}$ Annual Conference of the Australian Agricultural and Resource Economics Society, Adelaide, 10-12 February 2010. (URL http://ageconsearch.umn.edu/handle/59100, accessed 6 Nov 2012)

Marshall, G.R., McNeill, J.M. and Reeve, I.J. (2011). Economics for Accountability in CommunityBased Environmental Governance, Institute for Rural Futures. (University of New England: Armidale.)

McAlinden, D., Sparks, T., Burnside, D. and Stelfox, L. (2003). Salinity Investment Framework Interim Report- Phase 1, Salinity and Land Use Impacts, Report No SLUI 32. (Department of Environment: Perth.)

McKenney, B.A. and Kiesecker, J.M. (2010). Policy development for biodiversity offsets: A review of offset frameworks, Environmental Management 45, 165-176.

Meyer, B.C. and Grabaum, R. (2008). MULBO: Model Framework for multicriteria landscape assessment and optimization. A support systems for spatial land use decisions, Landscape Research 33, 155-179.

Pannell, D.J. (2005). Farm, food and resource issues: Politics and dryland salinity, Australian Journal of Experimental Agriculture 45, 1471-1480.

Pannell, D.J. (2008). Public benefits, private benefits, and policy intervention for land-use change for environmental benefits, Land Economics 84, 225-240. 
Pannell, D.J. (2009). Technology change as a policy response to promote changes in land management for environmental benefits, Agricultural Economics 40, 95-102.

Pannell, D.J. and Roberts, A.M. (2009). Conducting and delivering integrated research to influence land-use policy: salinity policy in Australia, Environmental Science and Policy 12, 1088-1099.

Pannell, D.J. and Roberts, A.M. (2010). The National Action Plan for Salinity and Water Quality: A retrospective assessment, Australian Journal of Agricultural and Resource Economics, 54, 437-456.

Pannell, D.J. and Wilkinson, R. (2009). Policy mechanism choice for environmental management by non-commercial "lifestyle" rural landholders. Ecological Economics 68, 2679-2687.

Pannell, D.J., Marshall, G.R., Barr, N., Curtis, A., Vanclay, F. and Wilkinson, R. (2006). Understanding and promoting adoption of conservation practices by rural landholders. Australian Journal of Experimental Agriculture 46, 1407-1424.

Pannell, D., Ridley, A., Seymour, E., Marsh, S. and Wilkinson, R. (2008). Capacity building in regional NRM: Issues in prioritisation, planning and implementation of environmental works at the regional level. RIRDC Publication No. 08/181, RIRDC Project No UWA-92A. (RIRDC: Canberra.) Available online: https://rirdc.infoservices.com.au/items/08-181 (accessed 5 April 2012).

Pannell, D.J., Roberts, A.M., Park, G., Alexander, J., Curatolo, A. and Marsh, S. (2012). Integrated assessment of public investment in land-use change to protect environmental assets in Australia, Land Use Policy 29, 377-387.

Park, G., Roberts, A., Alexander, J., McNamara, L. and Pannell, D. (2013). The quality of resource condition targets in regional natural resource management in Australia, Australasian Journal of Environmental Management, (forthcoming).

Pezzey, J.C.V. (2003). Emission taxes and tradeable permits: A comparison of views on long-run efficiency, Environmental and Resource Economics 26, 329-342.

Ridley, A., and Pannell, D.J. (2005). The role of plants and plant-based R\&D in managing dryland salinity in Australia, Australian Journal of Experimental Agriculture 45, 1341-1355.

Roberts, A. and Pannell, D. (2009) Piloting a systematic framework for public investment in regional natural resource management: dryland salinity in Australia, Land Use Policy 26, 1001-1010.

Roberts, A.M. Pannell, D.J. Doole, G. and Vigiak, O. (2012). Agricultural land management strategies to reduce phosphorus loads in the Gippsland Lakes, Australia, Agricultural Systems 106, 11-22.

Seymour, E., Pannell, D., Roberts, A., Marsh, S. and Wilkinson, R. (2008). Decision making by catchment management organisations in Australia: current processes and capacity gaps, Australasian Journal of Environmental Management 15, 15-25. 
Sparks, T., George, R., Wallace, K., Pannell, D., Burnside, D. and Stelfox, L. (2006). Salinity Investment Framework Phase II, Salinity and Land Use Impacts Series Report No. SLUI 34, (Department of Water: Perth.)

Stoneham, G., Chaudhri, V., Ha, A. and Strappazzon, L. (2003). Auctions for conservation contracts: An empirical examination of Victoria's BushTender trial, Australian Journal of Agricultural and Resource Economics 47, 477-500.

Weinberg, M., and Claassen, R. (2006). Conservation Program Design: Rewarding Farm Practices versus Environmental Performance, Economic Brief Number 5. (United States Department of Agriculture: Washington D.C.) 
1. Inventory of

environmental assets

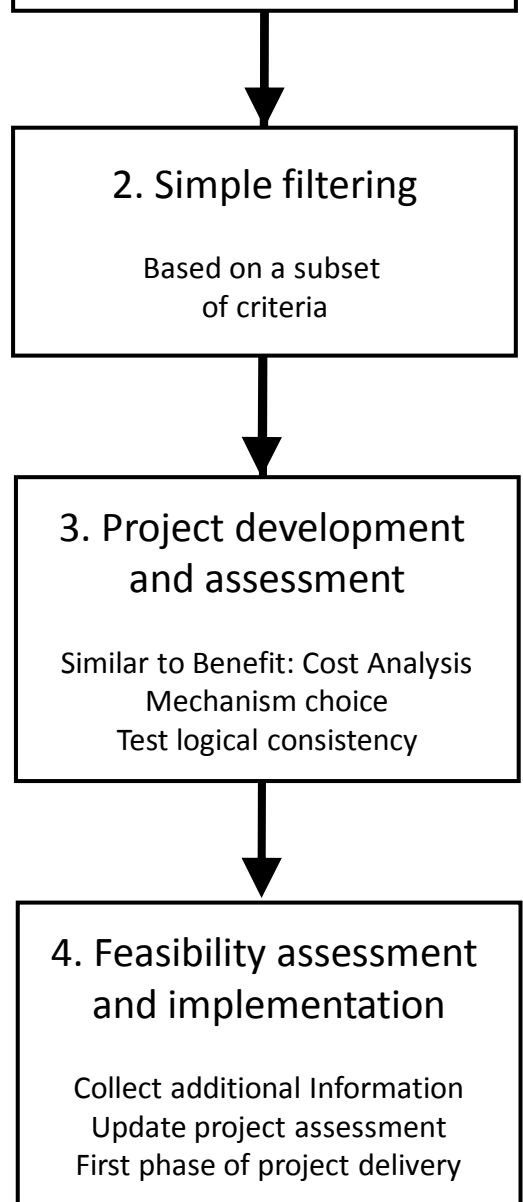

Figure 1. Steps of INFFER's project development, prioritisation and assessment process. 


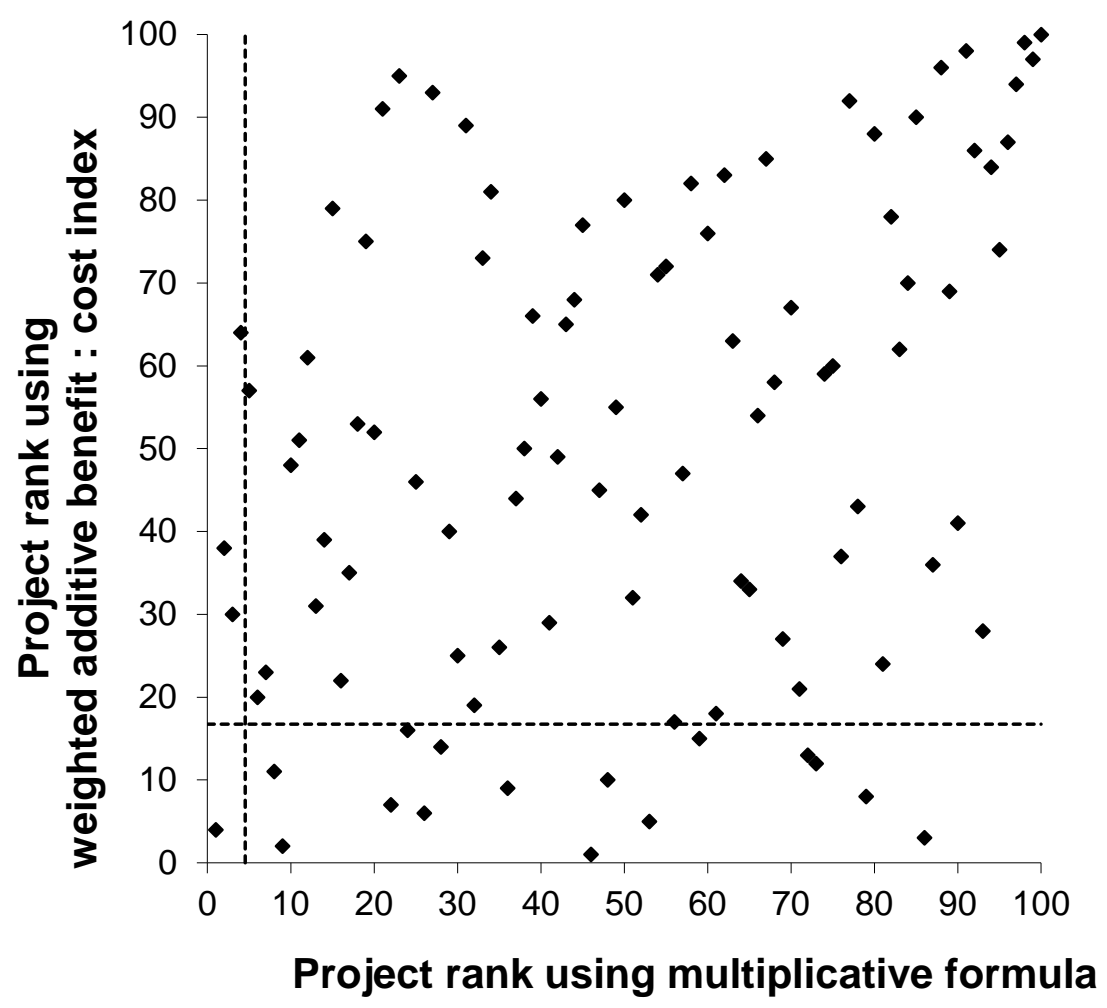

Figure 2. Comparison of project rankings from two different formulae: the multiplicative formula of equation (1) and a weighted additive benefit: cost index. 